\title{
SIMULTANEOUS OPTIMIZATION OF MACHINE AND TOOL PARAMETERS FOR EDM USING WC/Co P/M ELECTRODE MADE WITH MICRON AND NANO SIZED PARTICLES
}

\author{
Nadimpalli Sarada Purnima ${ }^{1}$, Pujari Srinivasa Rao ${ }^{2, *}$, Siva Prasad Dora ${ }^{2}$ \\ ${ }^{I}$ Department of Mechanical Engineering, GVP College for PG and Degree Courses, \\ Visakhapatnam, India \\ ${ }^{2}$ Department of Mechanical Engineering, GITAM, Visakhapatnam, India
}

Received 14.11.2020

Accepted 11.12.2020

\begin{abstract}
Multi-response characteristic optimization is the most desired aspect of the components produced from electric discharge machining (EDM). Obtaining the optimal combination of parameters for surface roughness (SR) and micro-hardness $(\mathrm{MH})$ is always a challenging task as the machining parameters favourable to one performance measure adversely affects the other. The present paper deals with the simultaneous optimization of SR and $\mathrm{MH}$ of D2 alloy steel during EDM with tungsten carbide (WC)/cobalt (Co) P/M electrode by considering electrode and machine tool parameters. Experimental run order was planned with Taguchi's orthogonal arrays (OA) and in the present investigation, it is based on L18 OA. The analysis of variance (ANOVA) performed for the grey relational grade (GRG) showed that the tool parameter "particle size" (PS) is the most influential factor (61.43\%) for simultaneous improvement of performance measures. The $\mathrm{P} / \mathrm{M}$ electrode made of fine particle size (i.e., at nano level) has improved the process stability and reduced the arcing and short-circuiting results in reduced surface roughness. Simultaneously, the formation of the hard intermetallic phase's viz., Fe3C, Cr23C6, W2C, Fe6W6C, and Cr2Fe14C on the EDMed surface has increased the surface hardness. The optimal set of parameters was validated through confirmation experiments.
\end{abstract}

Keywords: Simultaneous optimization; Grey relational analysis (GRA); EDM, P/M electrode.

${ }^{*}$ Corresponding author: Pujari Srinivasa Rao,pujari.vizag@gmail.com 


\section{Introduction}

EDM is the most common method for machining difficult to machine materials like high strength and high thermal resistant materials. The removal of material is achieved by an electric discharge between workpiece and tool electrodes with dielectric fluid as a medium. Because of high temperatures produced at the point of contact, the material is dislodged from both the workpiece and tool electrodes [1]. The constituents of tool and dielectric particles migrate towards the workpiece and deposit on the surface leading to surface modification [2]. Surface modification through the transfer of material is one of the key machining processes for the die and mould industry. Surface modification improves the properties of the surface viz., hardness, wear, and corrosion resistance, etc. The lack of all the desirable properties on a single EDM tool electrode for improvement of above mentioned properties led to the researchers focused on developing a composite tool electrode produced through $\mathrm{P} / \mathrm{M}$ method. This is among the least expensive method for the manufacturing of tool electrodes. Machining with P/M electrodes increases resistance to wear and hardness of components when compared to components machined with solid traditional electrodes, but at the same time, surface roughness also increases $[3,4]$. So it necessitates the development of a mechanism for simultaneous enhancement of properties for improved surface integrity.

Most of the research work in the past few years has been carried out in the area of simultaneous optimization of various performance measures in electric discharge machining. But, the majority of the reported literature concentrated on optimizing machining parameters only and very less on tool electrodes in general and limited on the influence of particle size variations in particular. Here, some of the literature on simultaneous optimization of various performance measures in EDM and their findings are presented. Chundru et al. [5] examined the surface modification studies of powder metallurgy electrodes by varying the particle sizes from nano to micro size and found the influence of nano particle size electrodes on various performance measures. Patowari et al. [6] studied the distinctions in mass transfer rate, the thickness of the white layer, and SR while machining of C-40 steel with W/Cu electrode (P/M). Kumar et al. [7] machined the $\mathrm{AA}_{7050} \mathrm{~B}_{4} \mathrm{C}$ by $\mathrm{EDM}$ route and estimated the performance measures using GRA technique. They obtained better results for an optimal combination of machining parameters by Grey-Taguchi technique than TOPSIS-Taguchi technique. Balraj and Krishna et al. [8] conducted the experiments on EDM and found that the combined effect of Taguchi and Grey relational analysis approach was effective in determining the optimum machining parameters. Shivade and Shinde et al. [9] done the machining process on D3 tool steel and optimized the various performance measures and found that peak current is the most significant parameter affecting multi-objective characteristics and proved the potential of grey relational analysis in obtaining parameters for simultaneous improvement of performance measures. The existing literature clearly shows that by careful selection and setting of parameters, it is possible to machine the components at optimal machining conditions. This combination gives optimal results for a particular machining condition or environment. The setting of parameters is more complex if it needs to simultaneously improve the performance measures as per the industrial requirements. The EDM is not only used for machining purposes, it is also used for modification of work piece surface by deliberate deposition of electrode material uniformly throughout the surface with a required hard and wear resistant material [10]. Further, the past research is concentrated only on optimizing the 
machine tool parameters, and very little attention was paid on the parameters related to tool electrodes made through $\mathrm{P} / \mathrm{M}$ route.

The particle size used for making electrodes through P/M method should be as small as possible (fine particles) for improved stability of the arc during machining [11, 12]. With the use of coarser particles, the chances for short-circuiting will be more, which decreases the machining efficiency and the quality of the surface machined. The influence of particle size utilized for the making of P/M electrodes and its effect on various performance measures are rarely studied. Hence, the authors of the present paper had studied the influence of P/M electrode fabricated by varying the particle size ranging from nano to micron size [13]. The existing literature mostly focused on the simultaneous optimization of various performance measures by considering only the machining parameters. So there is a dearth of information about the influence of tool parameters on simultaneous optimization in general and P/M electrodes fabricated with nano particles in particular. Hence, the present study's primary focus is the simultaneous improvement of two performance measures viz., SR and $\mathrm{MH}$ using GRA in the machining of D2 steel with WC/Co P/M electrodes fabricated by varying particle sizes from nano to micron and a combination of both.

\section{Experimentation}

Experimental design and parameters selection

EDM machining operations were designed based on L18 $\left(2^{1} \times 3^{5}\right)$ OA by considering six parameters in which three machine tool parameters and another three parameters are related to the tool electrode, as given in table 1 . Here, the electrode polarity is of 2-level, and the remaining five parameters are of 3-levels. The remaining parameters are peak current, pulse-on-time, the particle size of EDM electrode, wt $\%$ of Co and compaction pressure. Machining was performed with the Electronica machine tool of smart CNC S-50 model on D2 alloy steel and its set-up during machining with $\mathrm{P} / \mathrm{M}$ electrode, as shown in figures 1 (a) \& (b) respectively. 
Table 1. Selected parameters, levels and their units.

\begin{tabular}{|c|c|c|c|c|c|}
\hline Factor & Symbol & Unit & Level-1 & Level-2 & Level-3 \\
\hline Polarity (POL) & A & ---- & $\begin{array}{l}\text { Positive } \\
\text { (Normal) }\end{array}$ & Reverse & - \\
\hline Peak Current (IP) & B & Amp & 10 & 20 & 30 \\
\hline $\begin{array}{l}\text { Pulse-on-time } \\
\text { (TON) }\end{array}$ & $\mathrm{C}$ & $\mu \mathrm{sec}$ & 75 & 150 & 225 \\
\hline Particle Size (PS) & $\mathrm{D}$ & ----- & NP (Nano) & $\begin{array}{l}\text { NMP (Nano } \\
\text { and Micron } \\
\text { mix) }\end{array}$ & $\begin{array}{c}\text { MP } \\
\text { (Micron) }\end{array}$ \\
\hline $\begin{array}{l}\% \mathrm{Co} \text { in } \\
\mathrm{WC} / \mathrm{CoP} / \mathrm{M} \\
\text { electrode }(\% \mathrm{Co})\end{array}$ & $\mathrm{E}$ & ----- & 8 & 10 & 12 \\
\hline $\begin{array}{l}\text { Compact Pressure } \\
\text { (CP) }\end{array}$ & $\mathrm{F}$ & $\mathrm{MPa}$ & 250 & 350 & 450 \\
\hline
\end{tabular}

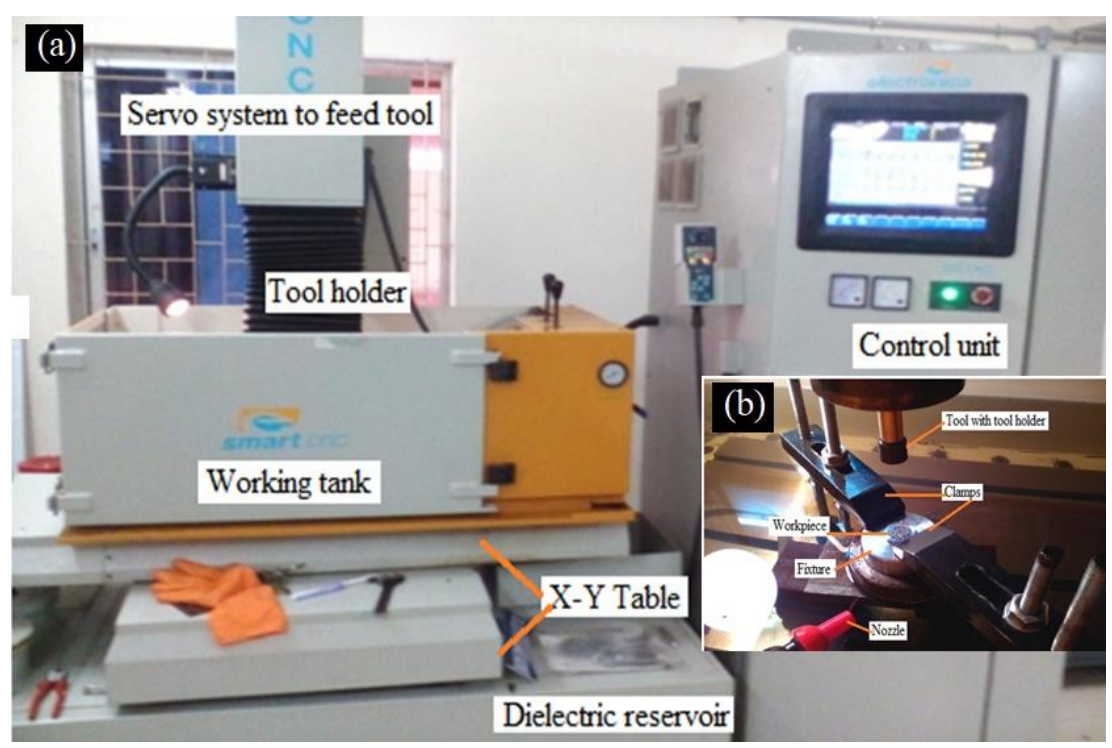

Fig. 1 (a) Smart CNC S-50 Electro discharge machine and (b) EDM set-up during machining with P/M electrode. 
The dielectric fluid used during EDM process is EDM oil. The D2 alloy steel is the most common material in die-making industries because of its high hardness, good wear resistance and excellent dimensional stability. But the formation of hard carbides due to rich in carbon and chromium elements results in increased temperature and tool wear rate during machining with conventional methods. Hence, it is difficult to machine material and generally preferred for machining with unconventional methods like the EDM process. The chemical composition presented in Table 2 confirms that the asreceived materials as D2 alloy steel and it is purchased from P.B. International, Mumbai, India. The JEOL JSM 6610LV SEM was utilized for testing of workpiece composition and for measuring white layer thickness. The machining on D2 steel workpiece was carried using WC/Co P/M electrodes and the EDMed samples were tested to measure SR and MH. Surface roughness was measured using Talysurf with a $0.8 \mathrm{~mm}$ cut-off length. Whereas, micro hardness was tested on DHV-1000, Vickers hardness tester with a load of 300 grams (2.94N). On each sample, five measurements were made at various points and the average value was recorded. The X-pert pro materials research diffraction (MRD) system was used for identifying the phases generated on the machined surface. For a clear insight, the obtained results were analyzed with the help of MINITAB software.

Table 2. Elemental composition of D2 steel alloy before machining.

\begin{tabular}{cccccc}
\hline $\mathrm{C}$ & $\mathrm{SI}$ & $\mathrm{Mn}$ & $\mathrm{S}$ & $\mathrm{P}$ & $\mathrm{Cr}$ \\
\hline $0.36-0.44 \%$ & $0.10-0.35 \%$ & $0.45-0.70 \%$ & $0.04 \%$ & $0.035 \%$ & $1.40 \%$ \\
\hline
\end{tabular}

Making of WC/Co Electrodes through P/M method

The selected powders of WC and Co were mixed at various proportions i.e., 92/8, $90 / 10$, and $88 / 12$ by weight. The nano and micron powders were used in the range of 20-40 $\mathrm{nm} \& 30-50 \mu \mathrm{m}$ for making of electrodes with nano powders designated as "NP electrodes" and with micron size powders designated as "MP electrodes" respectively. Another type of electrodes fabricated by combining the nano particles with micron sized particles at equal weight proportions and designated as "NMP electrodes". For mixing of the powder particles, the mortal and pastel method was used, and a liquid wax of approximately $1 \%$ of total weight was used as a bonding agent. This mixing was carried for more than 30 minutes. A universal compression testing machine was used to compact powder particles with the help of a cylindrical shaped die of diameter $15 \mathrm{~mm}$ and length $50 \mathrm{~mm}$. Then, powder particles were pressed at a pressure of 250, 350 and $450 \mathrm{MPa}$. The compacted green samples were then sintered in an argon atmosphere furnace by heating the samples at the rate of $10{ }^{\circ} \mathrm{C}$ per minute, starting from room temperature. The samples were hold for 60 minutes at the temperature of $350{ }^{\circ} \mathrm{C}, 950$ ${ }^{\circ} \mathrm{C}$ and at a peak temperature of $1300{ }^{\circ} \mathrm{C}$ and then the samples were furnace cooled at the rate of $50{ }^{\circ} \mathrm{C}$ to avoid cracks on the samples due to higher thermal gradient. For convenient holding of $\mathrm{P} / \mathrm{M}$ electrodes in the electrode holder, the samples were affixed with conductive glue to a brass rod of dimensions $\varnothing 12 \mathrm{~mm}$ x $50 \mathrm{~mm}$ length.

Figures. 2(a)-(c) shows the influence of particle size, \% Co in WC/Co electrode, and compaction pressure on density and resistivity properties. Higher density values were recorded for the electrodes made with nano size particles, lower wt $\%$ of cobalt (at $8 \mathrm{wt} \%$ of $\mathrm{Co}$ ) and at high $\mathrm{CP}$ of $450 \mathrm{MPa}$. In comparison, lower values of resistivity 
were recorded for the electrodes made of coarser particles (micro size particles), lower $\mathrm{wt} \%$ of cobalt (at $8 \mathrm{wt} \%$ of $\mathrm{Co}$ ) and at high CP of $450 \mathrm{MPa}$. The density and electrical resistivity values for all the $\mathrm{WC} / \mathrm{Co} \mathrm{P} / \mathrm{M}$ electrodes show some variation but the range is within the required limits desirable for any EDM electrode for performing efficient machining.

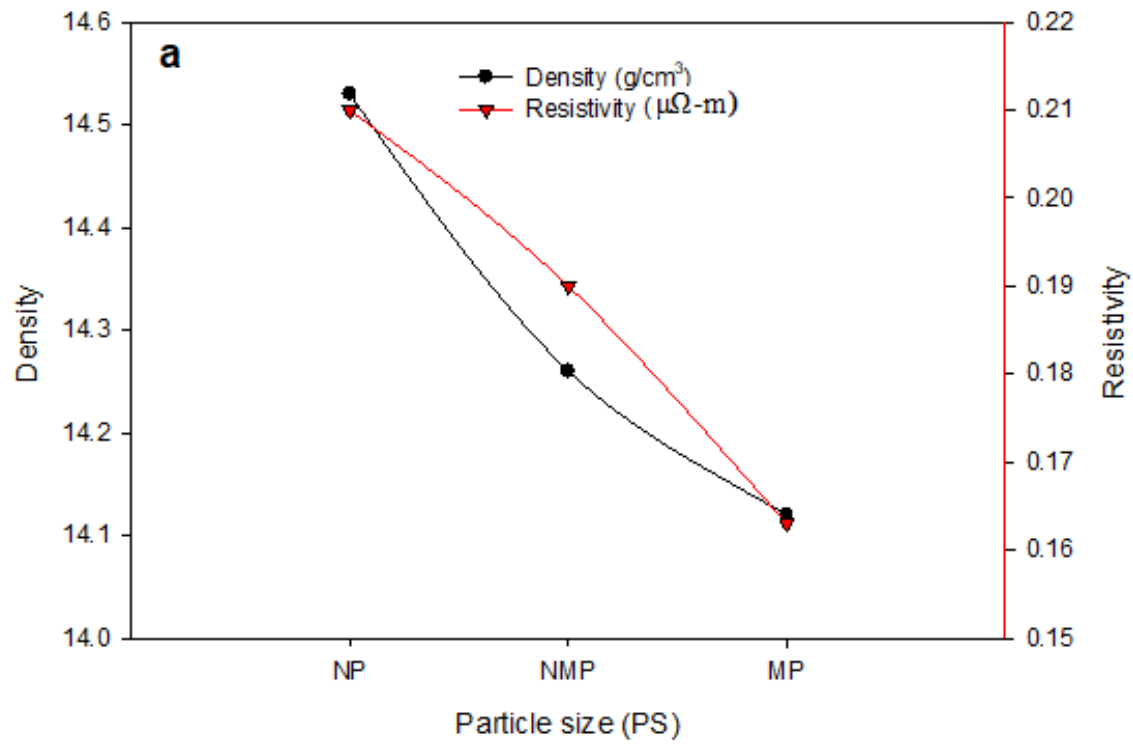

a)

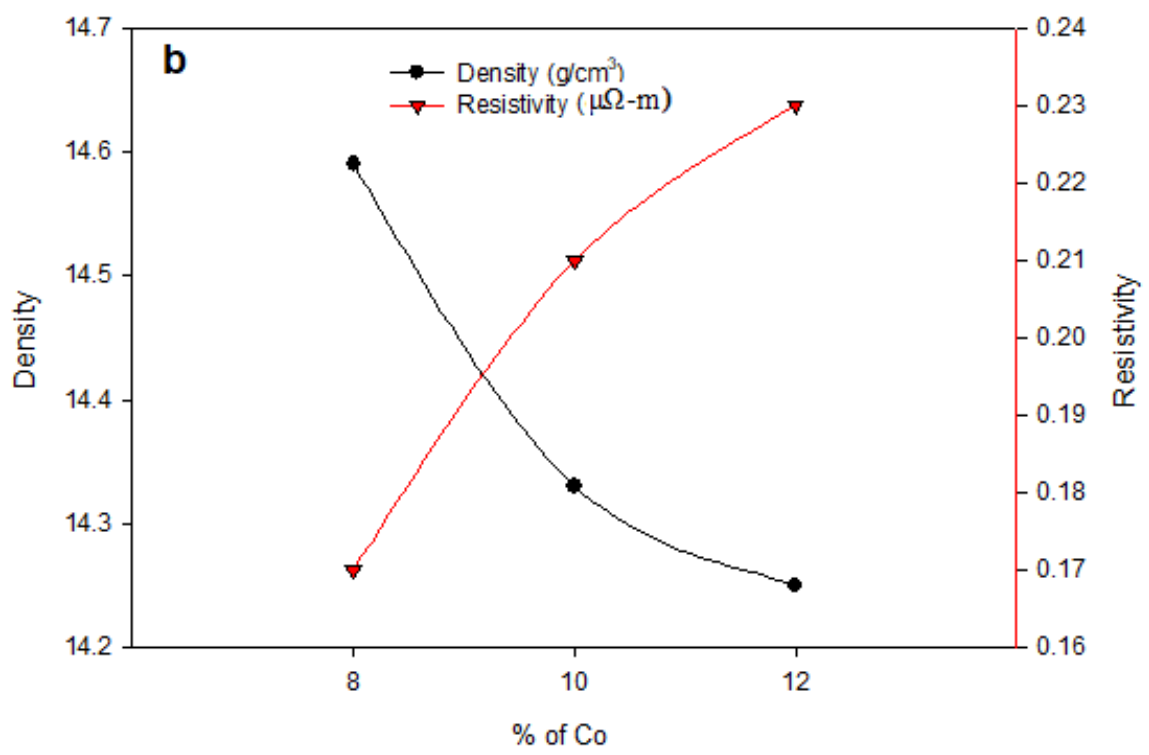

b) 


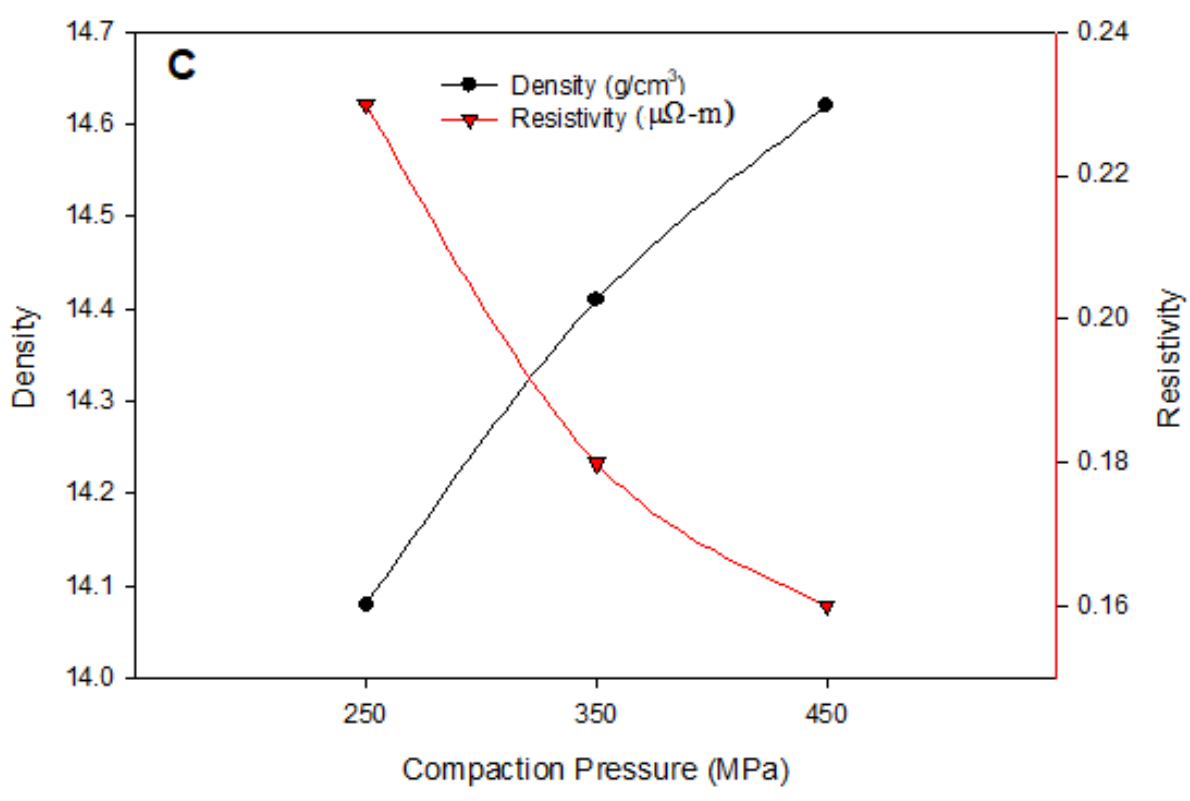

c)

Fig. 2. a) Influence of particle size, b) \% Co in WC/Co electrode, and c) compaction pressure on properties of density and resistivity.

\section{Results and Analysis}

Taguchi's method for individual response optimization

Taguchi's techniques use signal-to-noise $(\mathrm{S} / \mathrm{N})$ ratio analysis to find the optimal set of parameters to SR and MH. Equations (1) and (2) are used for the calculation of $\mathrm{S} / \mathrm{N}$ ratio values for the characteristics of "Lower is better" and "Higher is better" respectively. Here the surface roughness value should be as low as possible and micro hardness should be as high as possible hence the equations (1) and (2) are used for measuring earlier and later, respectively.

$$
\begin{aligned}
& \eta=-10 \log \frac{1}{n} \sum_{i=1}^{n} y^{2} \\
& \eta=-10 \log \frac{1}{n} \sum_{i=1}^{n}\left(\frac{1}{y^{2}}\right)
\end{aligned}
$$

Here ' $y$ ' represents measured performance value and ' $n$ ' is no. of times measured.

The experimental outcomes and $\mathrm{S} / \mathrm{N}$ ratios of $\mathrm{SR}$ and $\mathrm{MH}$ are presented in figure 3. The $\mathrm{S} / \mathrm{N}$ ratios were calculated for 18 experiments from which mean values for each parameter at different levels were computed. The level at which maximum value is 
obtained represents the greatest influence on a given performance measure. In the present investigation, the mean values of the $\mathrm{S} / \mathrm{N}$ ratio are represented in graphical form in Figures $4 \& 5$ for roughness and hardness, respectively.

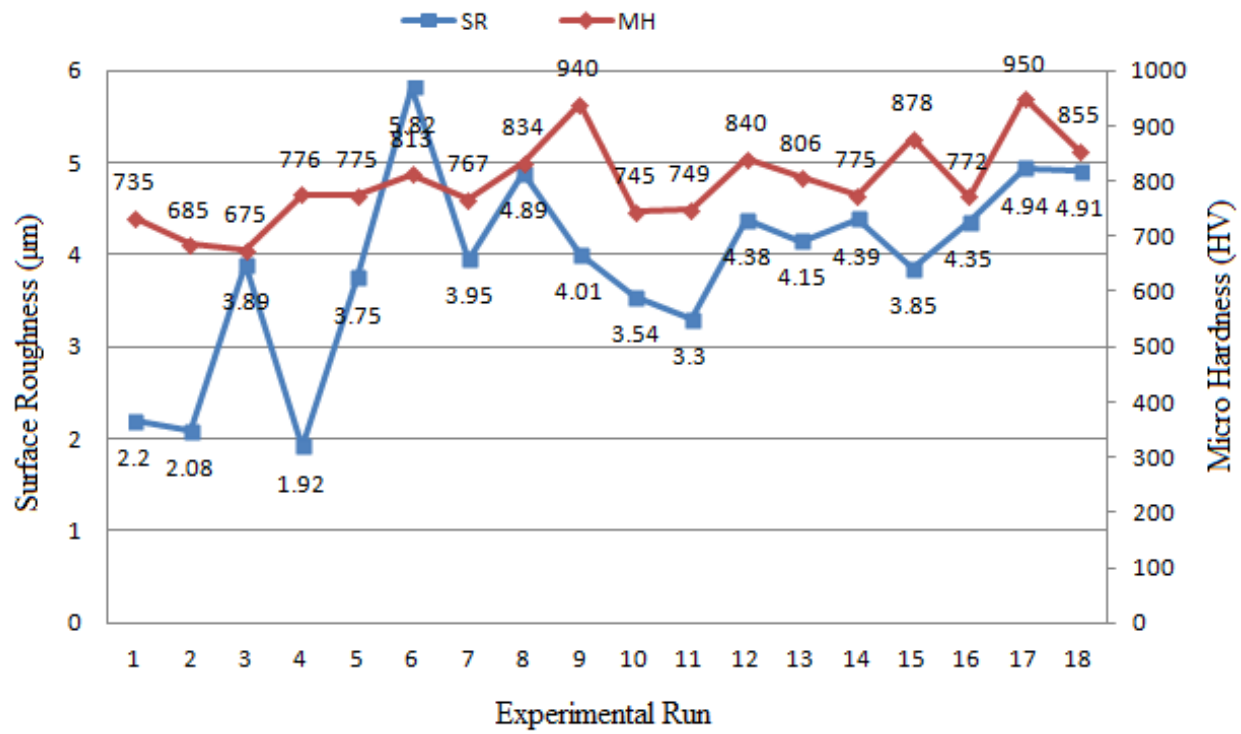

Fig. 3 Experimental values of surface roughness and micro hardness.

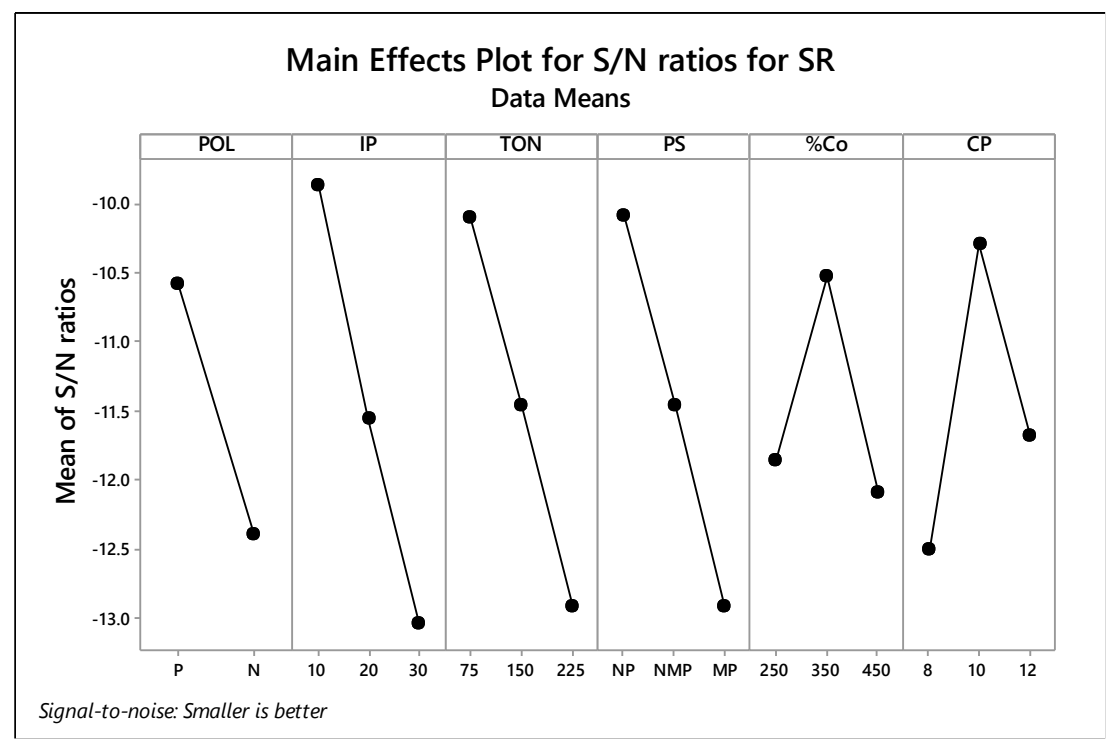

Fig. 4 S/N ratios at various levels of process parameters for $S R$. 


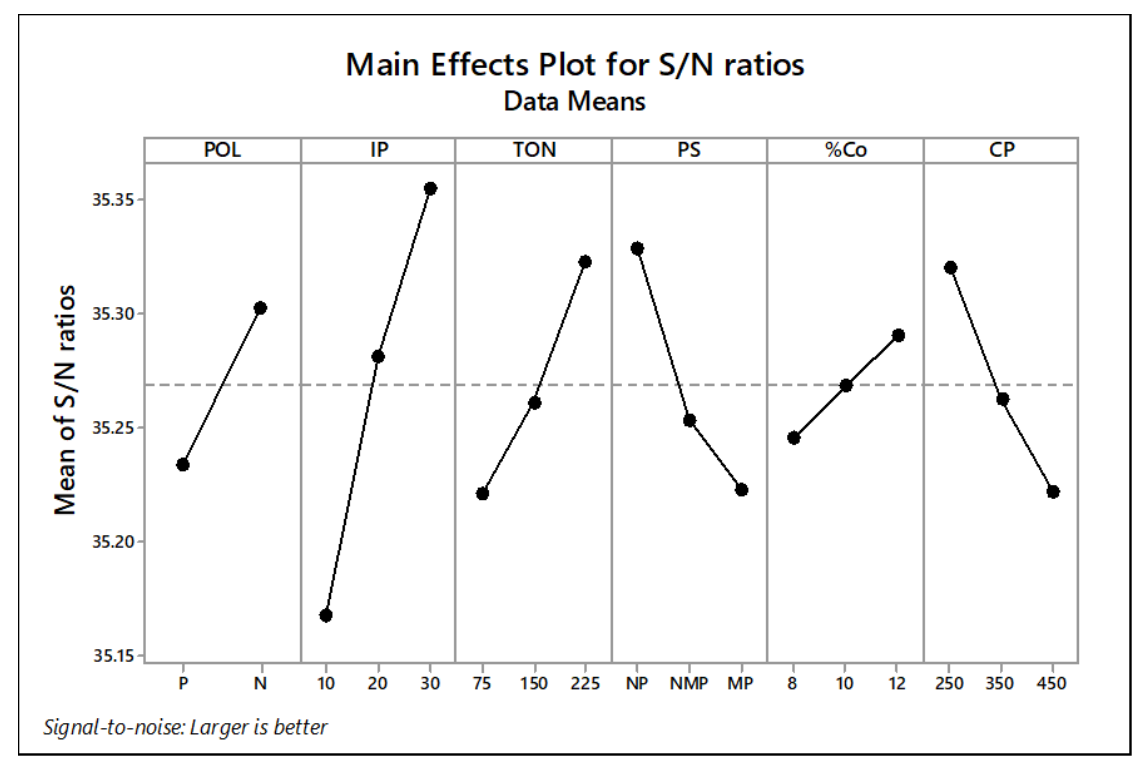

Fig. 5 S/N ratios at various levels of process parameters for $M H$.

The optimum combination of machining for improved SR is therefore achieved by choosing level 1 POL of positive polarity (A1), level 1 IP of 8 Amp (B1), level 1 TON of $75 \mu \mathrm{sec}(\mathrm{C} 1)$, level 1 PS of NP electrode (D1), level $2 \mathrm{wt} \%$ of Co i.e., $10 \mathrm{wt} \%$ (E2) and level $2 \mathrm{CP}$ of $350 \mathrm{MPa}(\mathrm{F} 2)$. So the optimum for SR during individual response optimization is A1B1C1D1E2F2. While the optimum parameter setting for improved $\mathrm{MH}$ is level 2 POL of negative tool electrode polarity (A2), level 3 IP of 12 Amp (B3), level 3 TON of $225 \mu \mathrm{sec}$ (C3), level 1 PS of NP electrode (D1), level $3 \mathrm{wt} \%$ of Co i.e., 12wt\% (E3) and level $1 \mathrm{CP}$ of $250 \mathrm{MPa}$ (F1). So the optimum/ideal combination for $\mathrm{MH}$ during individual response optimization is A2B3C3D1E3F1. For the simultaneous improvement of SR and $\mathrm{MH}$, the GRA technique is adopted in the present investigation.

\section{GRA for Simultaneous optimization}

Taguchi's technique is most commonly used to find individual (single) response optimization [14]. Today's industrial requirements are changed from obtaining superior quality characteristics of a single response to the simultaneous improvement of multiple quality characteristics [15]. In EDM, the number of parameters that influence the machining process is more and hence the level of complexity in finding the optimal set of process parameters is also increases [9]. In such situations, the grey-based Taguchi's technique can be successfully implemented for predicting the same [16].

So, the challenge for EDM researchers is to optimize multiple quality characteristics. GRA is a sophisticated multi-response analysis tool [17]. It calculates the independent grey relational coefficients for SR and $\mathrm{MH}$ for every individual experimental run and links between the ideal and actual normalized values. The GRG value is, therefore, determined by computing the average values of all GRC's. The highest GRG value is the best possible configuration for the simultaneous optimization of various performance measures. The grey relational framework significantly improved 
the different performance characteristics simultaneously and it is reported in earlier works [18-20]. The technique used in the present investigation for implementing GRA is described in figure 6 , and the same was used for optimizing the process parameters during machining of D2 steel for simultaneous enhancement of roughness and hardness.

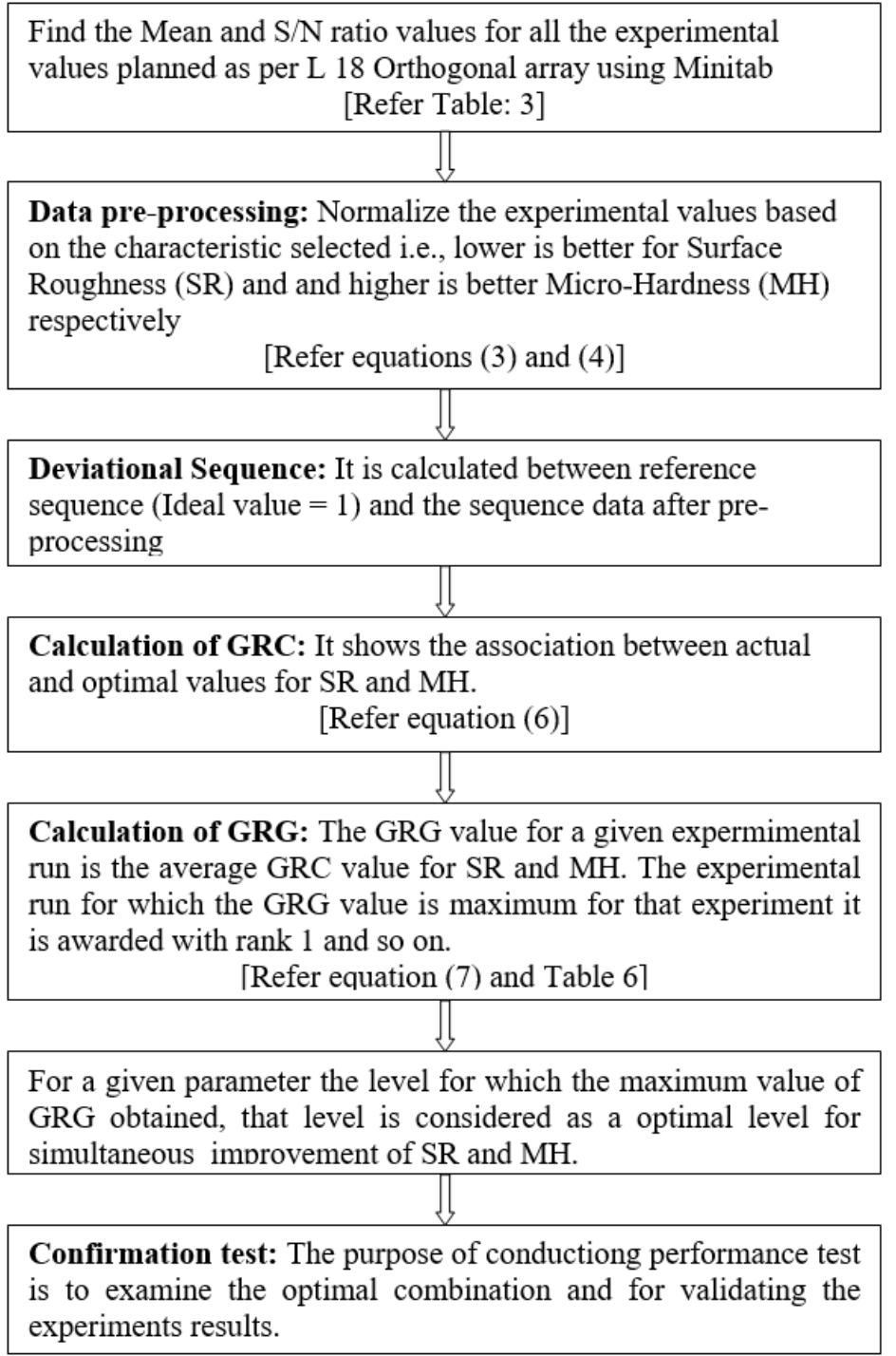

Fig. 6 Flow chart shows the method adopted for GRA.

First step: Processing of data

In the data processing stage, all the experimental values were normalized between zero and one. The selected characteristic for surface roughness is the type "Smaller is better" used to minimize the performance measure. In contrast, for 
microhardness, the selected characteristic is "larger is better" as it is used for maximizing the performance measure. The normalized values for each response of SR and $\mathrm{MH}$ were obtained using equations (3) and (4), respectively.

The smaller is the better $(S R) \boldsymbol{U}_{\boldsymbol{i}}^{*}(x)=\frac{\max U_{i}^{0}(x)-U_{i}^{0}(x)}{\max U_{i}^{0}(x)-\min U_{i}^{0}(x)}$

The larger is the better $(M H) \boldsymbol{U}_{i}^{*}(x)=\frac{U_{i}^{0}(x)-\min U_{i}^{0}(x)}{\max U_{i}^{0}(x)-\min U_{i}^{0}(x)}$

Where $\mathrm{U}_{i}^{*}(x)$ is the sequence data after pre-processing. $U_{i}^{0}(x)$ is mean value for original sequence and $x=1$ for surface roughness and $x=2$ for micro hardness; $i=1$ to 18 indicates experimental runs. $U_{0}^{*}(x)$ is the reference series as its value is 1 .

Second step: Calculation of GRC and GRG values

After normalization, the deviational sequence $\left(\Delta_{0 i}(x)\right)$ is calculated using equation(5) as shown below. It is calculated using the reference sequence $\boldsymbol{U}_{\mathbf{0}}^{*}(x)$ and the sequence data after pre-processing $\boldsymbol{U}_{\boldsymbol{i}}^{*}(x)$.

$$
\Delta_{0 i}(x)=\left|\boldsymbol{U}_{\mathbf{0}}^{*}(x)-\boldsymbol{U}_{\boldsymbol{i}}^{*}(x)\right|
$$

In order to show the association of ideal and actual normalized results GRC is determined. The normalized values for roughness and hardness, a deviational sequence for both the performance measures and GRC's for SR and MH are presented in table 3. The GRG $(\gamma)$ of all the performance characteristics is the average of the GRC's $\xi_{i}(x)$. The GRC values are computed using the equation given in (6), where the identification coefficient $(\zeta)$ value is 0.5 [21].

$$
\boldsymbol{G R C} \xi_{i}(x)=\frac{\Delta \min +\zeta \Delta \max }{\Delta_{0 i}(x)+\zeta \Delta \max }
$$

Once the GRC values have been obtained, then GRG $(\gamma)$ can be calculated by averaging all the GRC values related to each quality characteristic as shown in equation (7). The judgment of characteristic quality improvement in multi response optimization depends on the obtained GRG value.

$$
\boldsymbol{G R G} \quad \gamma_{i}=\frac{1}{n} \sum_{k=1}^{n} \xi_{i}(x)
$$

Table 3 shows the GRG values for all the experimental results given in L18 OA. The higher value of GRG shows that the value is closer to the ideal normalized value. Figure 7 shows grey relation grade in graphical form for all the experiments. The highest value of grade 0.7207 was obtained for the 4th experimental run; hence this is the best machining condition. 
Table 3.Grey relational analysis for eighteen runs of $S R$ and $M H$.

\begin{tabular}{|c|c|c|c|c|c|c|c|c|}
\hline \multirow{2}{*}{$\begin{array}{c}\text { Exp } \\
\text { No }\end{array}$} & \multicolumn{2}{|c|}{$\begin{array}{c}\text { Normalized } \\
\text { Values }\end{array}$} & \multicolumn{2}{|c|}{$\begin{array}{l}\text { Deviational } \\
\text { Sequence }\end{array}$} & \multicolumn{2}{|c|}{ GRC Values } & \multirow{2}{*}{ GRG } & \multirow{2}{*}{ Rank } \\
\hline & SR & $\mathrm{MH}$ & SR & $\mathrm{MH}$ & SR & $\mathrm{MH}$ & & \\
\hline 1 & 0.9282 & 0.2182 & 0.0718 & 0.7818 & 0.8744 & 0.3901 & 0.6323 & 5 \\
\hline 2 & 0.9590 & 0.0364 & 0.0410 & 0.9636 & 0.9242 & 0.4297 & 0.6770 & 4 \\
\hline 3 & 0.4949 & 0.0000 & 0.5051 & 1.0000 & 0.4757 & 0.3333 & 0.4045 & 18 \\
\hline 4 & 1.0000 & 0.3673 & 0.0000 & 0.6327 & 1.0000 & 0.4414 & 0.7207 & 1 \\
\hline 5 & 0.5308 & 0.3636 & 0.4692 & 0.6364 & 0.5159 & 0.4400 & 0.4780 & 10 \\
\hline 6 & 0.0000 & 0.5018 & 1.0000 & 0.4982 & 0.3333 & 0.5009 & 0.4171 & 17 \\
\hline 7 & 0.4795 & 0.3346 & 0.5205 & 0.6654 & 0.4900 & 0.429 & 0.4595 & 14 \\
\hline 8 & 0.2385 & 0.5782 & 0.7615 & 0.4218 & 0.3964 & 0.5424 & 0.4694 & 13 \\
\hline 9 & 0.4641 & 0.9636 & 0.5359 & 0.0364 & 0.4827 & 0.9321 & 0.7074 & 2 \\
\hline 10 & 0.5846 & 0.2546 & 0.4154 & 0.7454 & 0.5462 & 0.4015 & 0.4739 & 12 \\
\hline 11 & 0.6462 & 0.2691 & 0.3538 & 0.7304 & 0.5856 & 0.4064 & 0.4960 & 8 \\
\hline 12 & 0.3692 & 0.6000 & 0.6308 & 0.4000 & 0.4422 & 0.5556 & 0.4989 & 7 \\
\hline 13 & 0.4282 & 0.4764 & 0.5718 & 0.5236 & 0.4665 & 0.4885 & 0.4775 & 11 \\
\hline 14 & 0.3667 & 0.3636 & 0.6333 & 0.6364 & 0.4412 & 0.4400 & 0.4406 & 15 \\
\hline 15 & 0.5051 & 0.7382 & 0.4949 & 0.2618 & 0.5026 & 0.6563 & 0.5795 & 6 \\
\hline 16 & 0.3769 & 0.3527 & 0.6231 & 0.6473 & 0.4452 & 0.4358 & 0.4405 & 16 \\
\hline 17 & 0.2256 & 1.0000 & 0.7744 & 0.0000 & 0.3923 & 1.0000 & 0.6962 & 3 \\
\hline 18 & 0.2333 & 0.6546 & 0.7667 & 0.3454 & 0.3947 & 0.5914 & 0.4931 & 9 \\
\hline
\end{tabular}

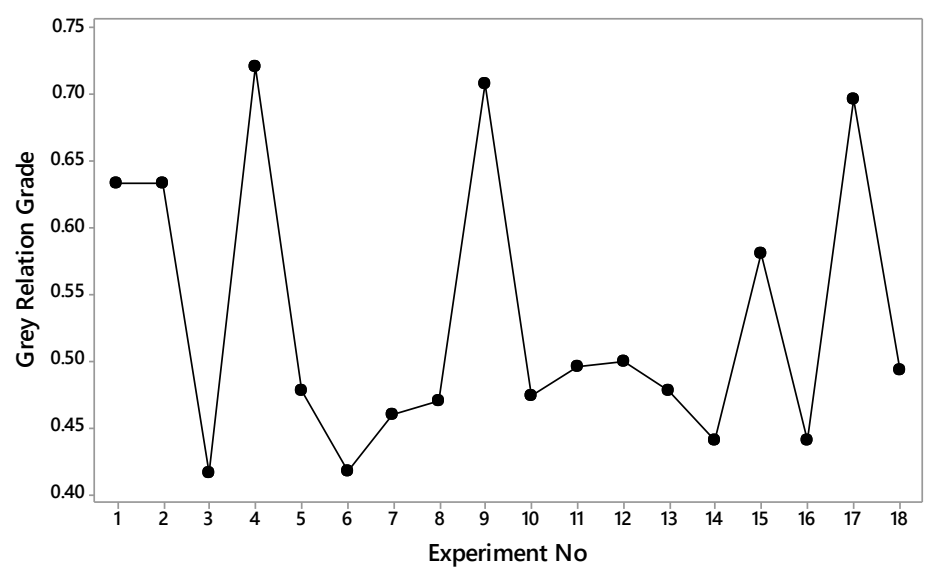

Fig. 7. GRG at each experimental run during multi-response optimization. 
The GRG value shows the extent of the connection between comparability and reference sequences and hence the highest value of grade indicates the strong correlation between these two. Depending on this investigation, one can decide on a grouping of levels, which gives the highest average response. Figure 8 displays the mean value of GRG values at distinct levels of every parameter and the dashed line means GRG value. The following set of parameters and their levels i.e., A1B3C2D1E2F2 indicates positive polarity, IP of 30A, TON of $150 \mu \mathrm{s}$, NP electrode, wt\% of Co of $10 \%$ and $\mathrm{CP}$ of $350 \mathrm{MPa}$ at which the maximum value of the GRG is obtained and hence represents the optimal combination of parameters.

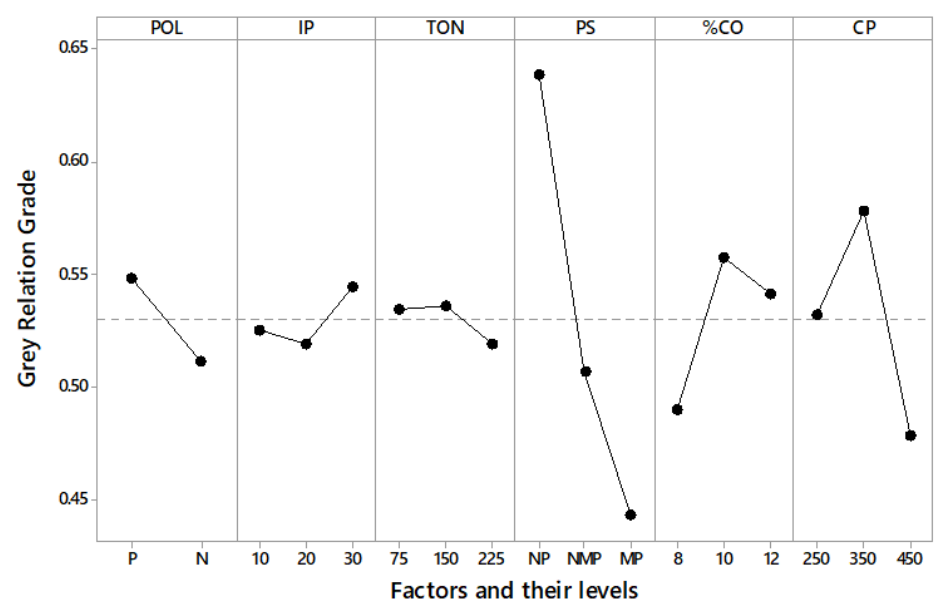

Fig. 8. GRG at each level for all the parameters.

\section{Step 3: Analysis of variance for GRG}

To find the influence of process parameters on $\mathrm{SR}$ and $\mathrm{MH}$, a statistical technique known as ANOVA is used. At each level, the GRG value for every parameter is found and the one with a maximum difference is ranked 1 followed by 2,3, and so forth. Table 4 shows that the parameter particle size attained rank 1 and shows major influence on the simultaneous improvement of both roughness and hardness. The surface alloying or modification occurs in the EDM process because of the migration of tool particles and particles of the dielectric medium due to pyrolysis. In the present investigation, the particle size of the EDM electrode at nano level (for NP electrodes) has shown a substantial reduction in the work piece's roughness. The migrated particle sizes for NP electrodes are comparatively smaller than the spark gap value, causing reduced arcing, reduced short-circuiting, and improved process stability resulting in reduced surface roughness. As the NP electrode particles are at nano level, they produce a high capillary force during sintering, making denser EDM electrodes. The high density of $\mathrm{P} / \mathrm{M}$ electrodes particles is tightly held together and hence reduced tool wear rate should be recorded. In spite of NP electrodes' lower thermal conductivity compared to MP and NMP electrodes, more heat is accumulated in the tool electrode. Hence, higher amount of tool material is dislodged from the surface and migrated towards the work surface. Increased surface alloying ability was observed for NP tool electrodes compared to MP and NMP tool electrodes. This leads to the generation of very hard 
inter-metallic phases viz., Fe3C, Cr23C6, W2C, Fe6W6C and $\mathrm{Cr} 2 \mathrm{Fe} 14 \mathrm{C}$ on the surfaces machined with NP electrodes consequently, higher micro hardness values were recorded. Figure 9 shows the intermetallic phases on the XRD pattern obtained when examining the surface machined at optimal parameter settings. Further, the combination of high TON and IP values increases the discharge energy during machining and more amount of material is transferred resulting in increased MH. ANOVA to GRG shows that the most significant parameter is given in Table 5 is "particle size" (PS) with a wt\% of $61.43 \%$, followed by compaction pressure (CP) of $18.3 \%$, \% Co of $8.86 \%$ and the remaining all other parameters with a minor influence on the performance of measures during simultaneous optimization of SR and MH. From the above, it is evident that the three electrode parameters particle size, compaction pressure and \%Co have a dominant influence compared to machine tool parameters of polarity, pulse on time and peak current during simultaneous optimization.

Table 4. Mean table of response for GRG values at different levels of parameters.

\begin{tabular}{ccccccc}
\hline Parameters & POL & IP & TON & PS & \% Co & CP \\
\hline Level-1 & 0.5518 & 0.5304 & 0.5341 & 0.6387 & 0.4898 & 0.5319 \\
Level-2 & 0.5107 & 0.5189 & 0.5429 & 0.514 & 0.5643 & 0.5855 \\
Level-3 & & 0.5444 & 0.5168 & 0.441 & 0.5396 & 0.4763 \\
Max-Min & 0.0411 & 0.0255 & 0.0261 & 0.1977 & 0.0745 & 0.1092 \\
\hline Rank & 4 & 6 & 5 & 1 & 3 & 2 \\
\hline
\end{tabular}

Table 5. ANOVA results for GRG.

\begin{tabular}{|c|c|c|c|c|c|c|c|c|}
\hline Factor & Level 1 & Level 2 & Level 3 & $\begin{array}{c}\text { Degree } \\
\text { of } \\
\text { freedom }\end{array}$ & $\begin{array}{l}\text { Sum of } \\
\text { squares }\end{array}$ & $\begin{array}{l}\text { Mean } \\
\text { square }\end{array}$ & $\begin{array}{c}\mathrm{F} \\
\text { value }\end{array}$ & $\begin{array}{c}\text { Contribution } \\
(\%)\end{array}$ \\
\hline POL & 0.5518 & 0.5107 & & 1 & 0.006299 & 0.006299 & 5.05 & 3.9 \\
\hline IP & 0.5304 & 0.5189 & 0.5444 & 2 & 0.002127 & 0.001064 & 0.85 & 0.99 \\
\hline TON & 0.5341 & 0.5429 & 0.5168 & 2 & 0.001057 & 0.000528 & 0.42 & 1.08 \\
\hline PS & 0.6387 & 0.514 & 0.4410 & 2 & 0.119724 & 0.059862 & 47.99 & 61.43 \\
\hline$\% \mathrm{Co}$ & 0.4898 & 0.5643 & 0.5396 & 2 & 0.014860 & 0.007430 & 5.96 & 8.86 \\
\hline $\mathrm{CP}$ & 0.5319 & 0.5855 & 0.4763 & 2 & 0.030044 & 0.015022 & 12.04 & 18.3 \\
\hline Error & & & & 6 & 0.007485 & 0.001247 & 27.69 & 5.4 \\
\hline
\end{tabular}




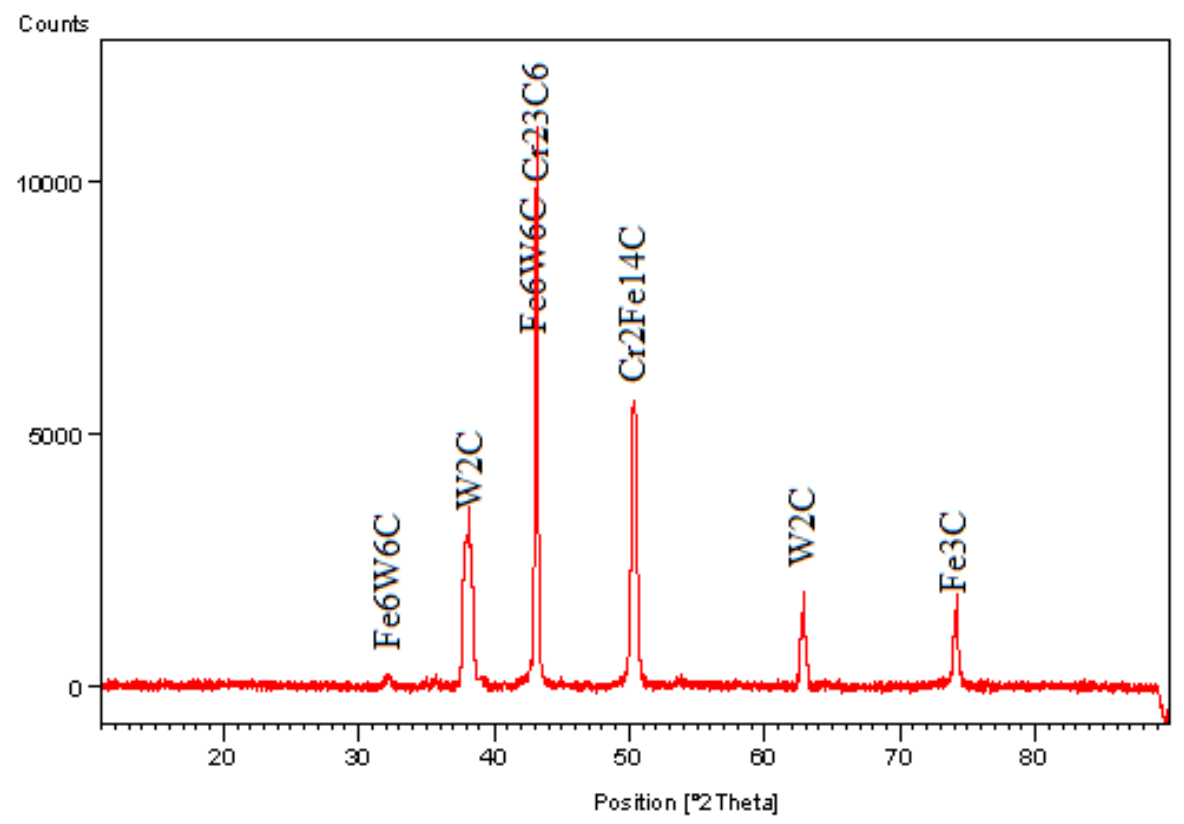

Fig. 9. XRD shows the generated intermetallics on the EDM surface at optimal condition.

The residual plots for surface roughness and micro hardness are shown in figures 10 and 11 respectively. It is demonstrated that the distribution of data points in a linear passion indicates that error terms are also distributed normally. The plot of fitted Vs residuals values and observation order should not form a recognizable pattern. The data collection time-order is helpful in testing the residuals' presumption of independence. The data points are structureless, irregular and randomly distributed. So the ANOVA assumptions are proved to be valid; hence the inferences made on this table proved to be valid. The percent contribution of each parameter in influencing the GRG is presented in figure 12. It clearly shows the dominant contribution of particle size (PS) parameter in influencing the GRG value during simultaneous enhancement of roughness and hardness. 


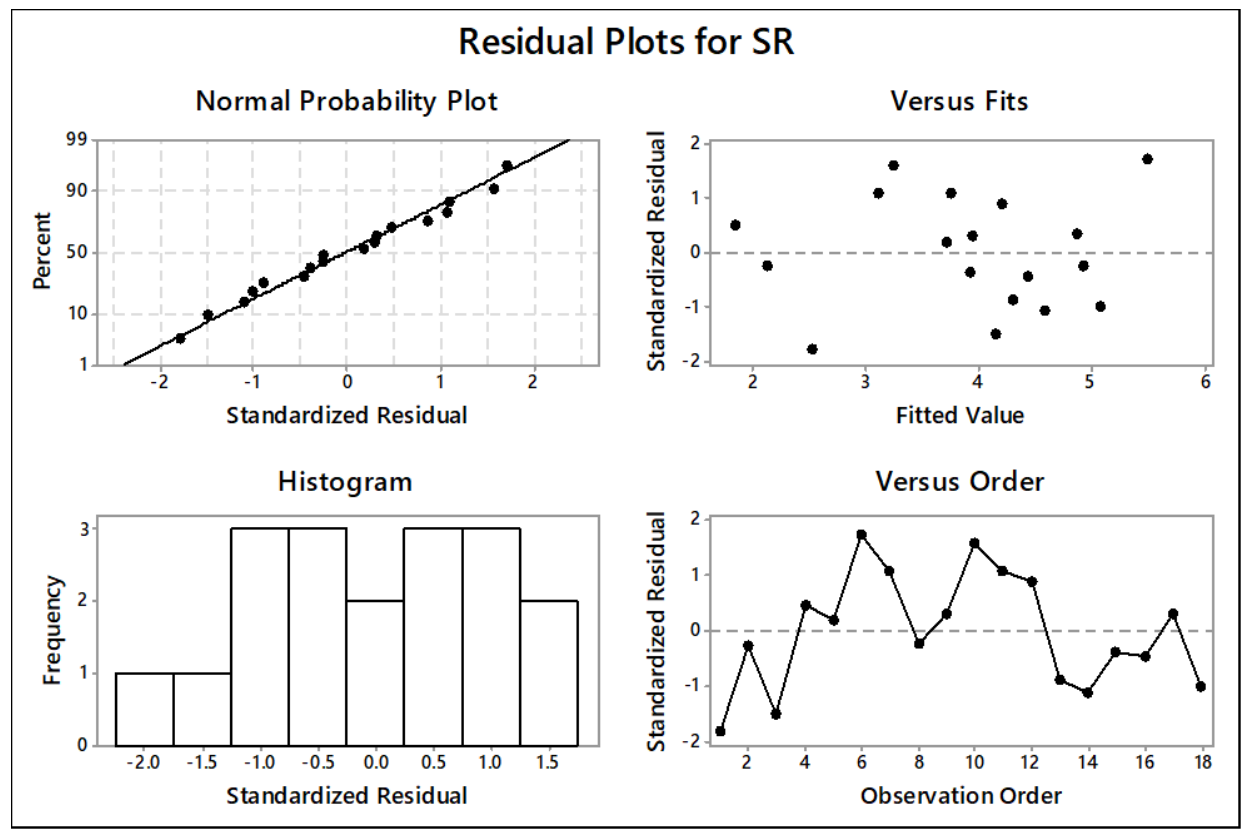

Fig. 10. Residual plot generated for the results of Surface Roughness test.

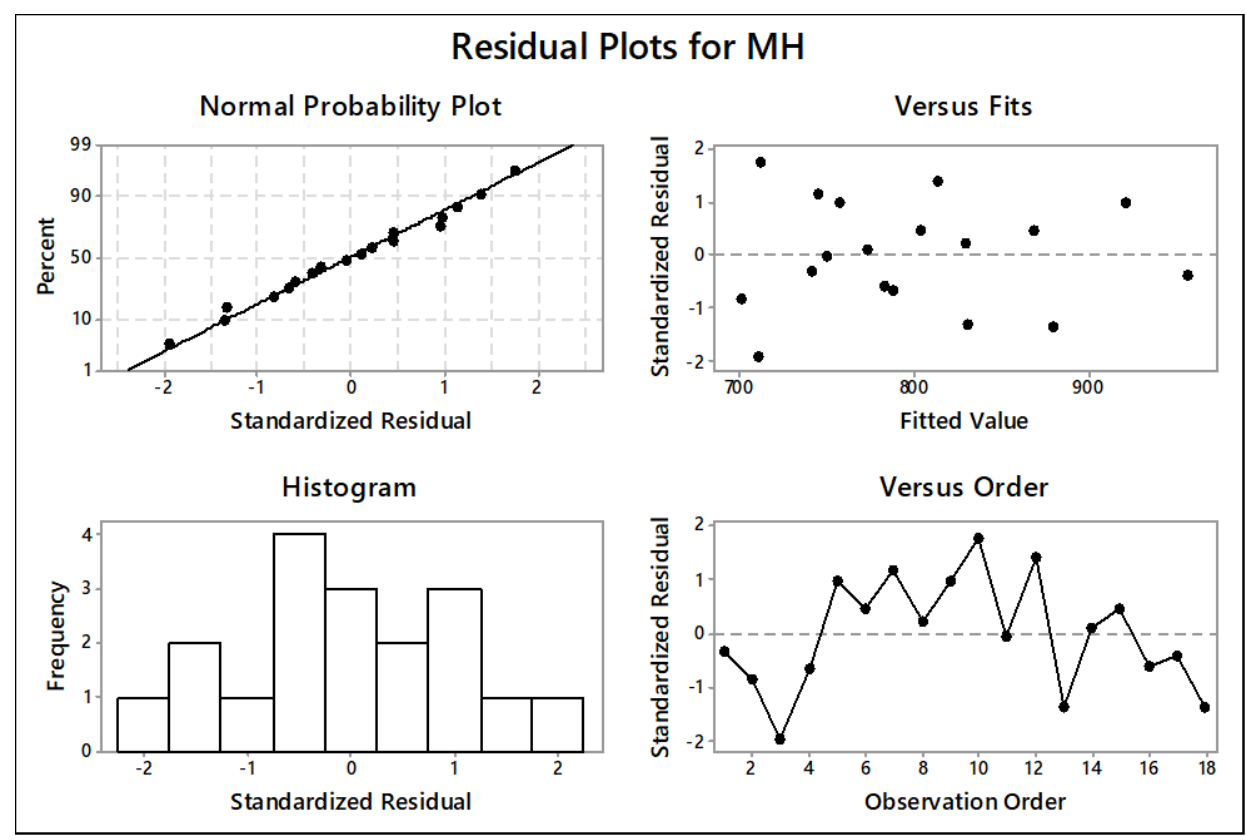

Fig. 11. Residual plot generated for the results of Micro-Hardness test. 


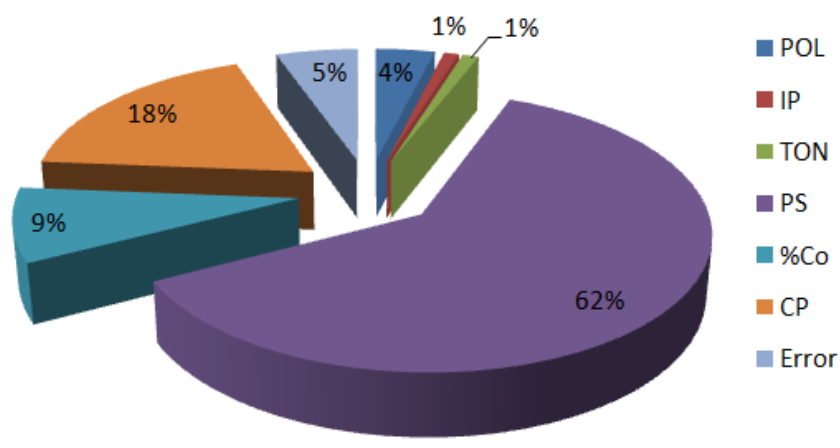

Fig. 12. Percentage contribution to GRG by each parameter.

\section{Step 4: Confirmation experiment}

To confirm the enhancement of performance measures a separate experiment was designed at optimal levels of parameters which are assessed during experimental analysis [22]. The enhancement of performance measures can be confirmed by calculating the GRG value at an optimal combination of parameters and then comparing them with the GRG value obtained at the initial set of parameters. The GRG value at an optimal combination is measured with the help of equation (8).

$$
\alpha_{o p t}=\alpha_{m}+\sum_{j=1}^{k}\left(\alpha_{j}-\alpha_{m}\right)
$$

Where, $\alpha_{\text {opt }}$ is the estimated GRG at optimal condition, $\alpha_{m}$ is the GRG value for total mean, $\alpha_{\mathrm{j}}$ is the mean GRG value at an optimal level of each parameter and $\mathrm{k}$ represents the total count of parameters that influences quality features. The experimental values of SR and $\mathrm{MH}$ at optimal conditions are $2.52 \mu \mathrm{m}$ and $890 \mathrm{HV}$ respectively as displayed in table 6 and there is an improvement in the GRG. The marginal increase in the white layer thickness of $\sim 62 \mu \mathrm{m}$ was observed on the specimen machined at optimal combination i.e., A1B3C2D1E2F2. This is slightly higher than the value of $\sim 47 \mu \mathrm{m}$, which was observed on the specimen machined at initial machining conditions i.e., A1B1C1D1E1F1, as shown in figures 13(a) \& (b) respectively. Further, the predicted and experimental values were observed to be closer, which indicates the suitability of the proposed statistical method in the present study.

Table 6. Predicted and experiment results for $S R$ and $M H$.

\begin{tabular}{lccc}
\hline & & \multicolumn{2}{c}{ Optimal Machining Parameters } \\
Setting level & Initial data & Predicted & Experimental \\
\hline SR $(\mu \mathrm{m})$ & A1B1C1D1E1F1 & A1B3C2D1E2F2 & A1B3C2D1E2F2 \\
MH $(\mathrm{HV})$ & 2.20 & -- & 2.52 \\
GRG value & 735 & -- & 890 \\
Improvement & 0.6323 & 0.75479 & 0.73045 \\
in GRG Value & -- & 0.12249 & 0.09815 \\
\hline
\end{tabular}



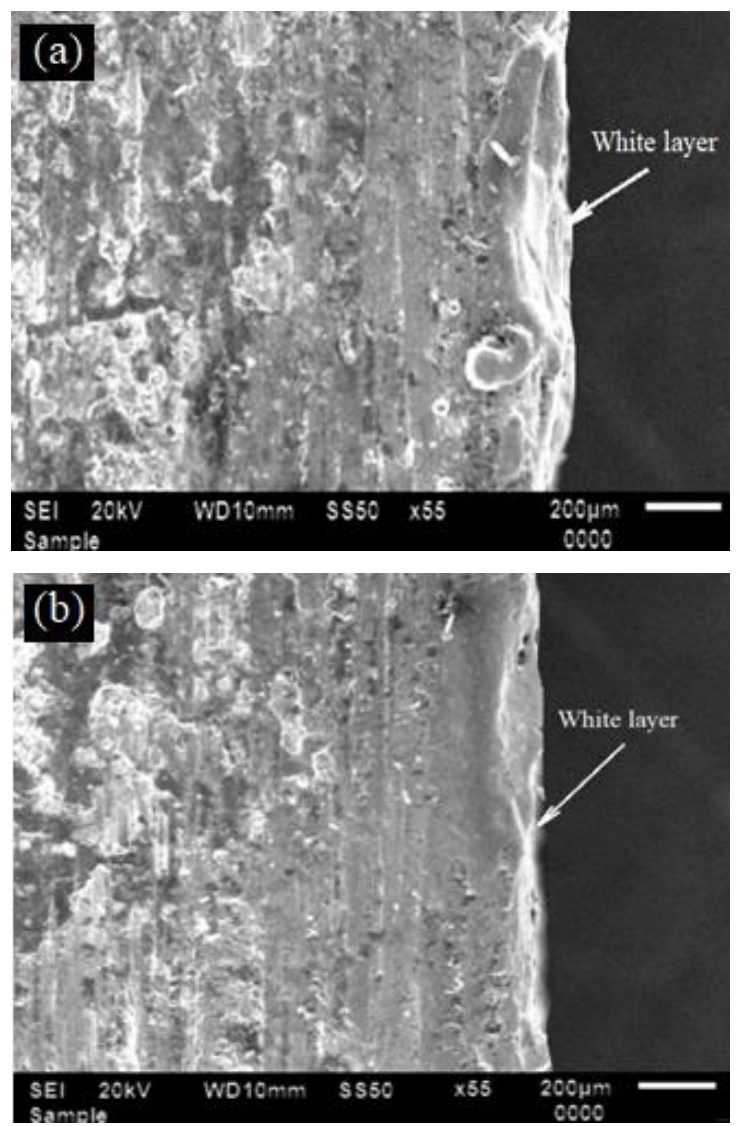

Fig. 13. (a) \& (b) White layer thickness obtained at optimal machining and initial machining conditions respectively.

\section{Conclusions}

The following conclusions are drawn from the present investigation on the simultaneous optimization of SR and MH by taking into account of machine tool and electrode parameters.

1. During single response optimization, the parameter peak current is found to be the most influential parameter, then parameters particle size and pulse-on-time follow. So, it clearly shows the dominance of machining tool parameters over tool parameters in controlling the individual responses viz., surface roughness and micro hardness.

2. The ANOVA for GRG shows that the parameter particle size has a significant influence with a percent contribution of $61.43 \%$, followed by CP with an $18.3 \%$ and $\% \mathrm{Co}$ with an $8.86 \%$, so clearly indicates the importance of electrode parameters during simultaneous optimization of SR and $\mathrm{MH}$ when compared to machine tool parameters. 
3. The SR and MH values at the initial machining condition (A1B1C1D1E1F1) are $2.20 \mu \mathrm{m}$ and $735 \mathrm{HV}$, respectively. Whereas, at optimum parameter setting (A1B3C2D1E2F2) the surface roughness (SR) and micro hardness $(\mathrm{MH})$ values are $2.52 \mu \mathrm{m}$ and $890 \mathrm{HV}$, respectively. The improvement in GRG value at optimal condition indicates the improvement of overall performance measures.

4. Obtaining the lowest SR and highest $\mathrm{MH}$ of $1.92 \mu \mathrm{m}$ and $950 \mathrm{HV}$ at experiments 04 and 17 respectively indicates the predominant effect of NP electrode in achieving process stability and surface alloying.

5. In the present investigation, the use of NP electrodes made with nano size particles has reduced the arcing and short-circuiting and hence reduced the SR. At the same time nano particles are more reactive because of their high surface area, which promotes more surface alloying/modification than MP and NMP tool electrodes. So, the generation of very hard intermetallics viz., Fe3C, Cr23C6, W2C, Fe6W6C, and $\mathrm{Cr} 2 \mathrm{Fe} 14 \mathrm{C}$ could be a reason for enhanced hardness at optimum machining condition.

6. The formation of carbides due to rich in carbon, chromium, and other elements was the reason for not preferred to machine D2 alloy steel with conventional methods. These carbides increase the temperature and hence increase the tool wear rate. Hence, the selection of optimum machining parameters in the machining of D2 alloy steel, which is carried in the present work, is justified.

\section{Acknowledgments:}

The authors wish to thank SERB - DST, New Delhi, India for the financial help in performing this research project vide sanction No. SB/ FTP/ ETA - 0070/ 2014. 


\section{References:}

[1] A. Y. Joshi and Anand Y. Joshi: Heliyon, 5(2019) 1-12.

[2] P.K. Patowari, U.K. Mishra, P. Saha, P.K. Mishra: Materials and Manufacturing Processes, 26(2011) 668-676.

[3] A.S. Gill and S. Kumar: Proc Inst Mech Eng, Part B, 232(2018) 438-450.

[4] C. Cogun, Z. Esen, A. Genc, F. Cogun, N. Akturk: Proc Inst Mech Eng, Part B, 230(2016) 2190-2203.

[5] V.R. Chundru, R. Koona., S.R Pujari: Arabian Journal of Science and Engineering, 44(2019) 1425-1436.

[6] P.K. Patowari, P.Saha, P.K. Mishra: Int J Adv Manuf Technol, 80(2015) $343-$ 360.

[7] A.Kumar, and R. N. Rai: Journal of the Institution of Engineers (India), Series D, 101(2020) 71-79.

[8] U. Shrinivas Balraj, A. Gopala Krishna: International journal of Manufacturing, Materials, and Mechanical Engineering, 4(2014) 103-121.

[9] A.S. Shivade, V.D. Shinde: Journal of Industrial Engineering international, 10 (2014) 149-162.

[10] Abu Qudeiri JE, Saleh A, Ziout A, Mourad AHI, Abidi MH, Elkaseer A: Materials, 12 (2019) 907.

[11] M. Shabgard, M.Seyedzavvar, H. Abbasi: Int J Adv Manuf Technol, 90(2017) 1203-1216.

[12] M.P.Samuel and P.K. Philip: Int J Mach Tool Manuf, 37(1997) 1625-1633.

[13] P. S. Rao, N.S. Purnima, N. S., D.S. Prasad: Mater Res Express, 6(2019) 1-15.

[14] M. Kumar, H. Singh: Cogent Engineering, 3 (2016) 1266123.

[15] P. Sengottuvel, V.Palanisamy, J. Arun, N.R.R. Anbusagar, J. HameedHussain: Applied Mechanics and Materials, 766-767 (2015) 867-872.

[16] L. Tang, Y.T. Du: The International Journal of Advanced Manufacturing, 70 (2014) 469-475.

[17] B. K. Tharian, E.Jacob, J.Johnson, V.Hari: Materials Today: Proceedings, 16(2019) 1013-1019.

[18] N. K. Chauhan, A. K. Das, S. Rajesha: Materials Today: Proceedings, 5(2018) 27178-27184.

[19] B. P Mishra and B.C. Routara: Materials Today: Proceedings, 4(2017) 74387447.

[20] K.Rajesh, K Anish, P.G Mohinder, S.Ajit, S.Neeraj: J Ind Eng Int, 11(2015) 459-472.

[21] M. Z. Hussain, S. Khan, P. Sarmah: Journal of King Saud UniversityEngineering Sciences, 32(2020) 274-286.

[22] P.Achuthamenon Sylajakumari, R.Ramakrishnasamy, G. Palaniappan: Materials, 11(2018) 1-17.

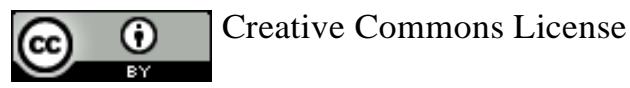

This work is licensed under a Creative Commons Attribution 4.0 International License. 